ENCYCLOPEDDIE Encyclopédie berbère

BERBERE

3 | 1986

3 | Ahaggar - Alī ben Ghaniya

\title{
Ain Naga
}

D. Grebenart

\section{(2) OpenEdition}

Journals

Édition électronique

URL : http://journals.openedition.org/encyclopedieberbere/840

DOI : $10.4000 /$ encyclopedieberbere.840

ISSN : 2262-7197

\section{Éditeur}

Peeters Publishers

\section{Édition imprimée}

Date de publication : 1 juillet 1986

Pagination : 335-337

ISBN : 2-85744-260-2

ISSN : 1015-7344

\section{Référence électronique}

D. Grebenart, « Ain Naga », Encyclopédie berbère [En ligne], 3 | 1986, document A120, mis en ligne le 01 décembre 2012, consulté le 13 octobre 2020. URL : http://journals.openedition.org/ encyclopedieberbere/840; DOI : https://doi.org/10.4000/encyclopedieberbere.840

Ce document a été généré automatiquement le 13 octobre 2020

(c) Tous droits réservés 


\section{Ain Naga}

\section{Grebenart}

1 Située en Algérie entre Djelfa et Messad, Aïn Naga est une source entourée de jardins à proximité desquels on rencontre un important gisement pré- historique et plusieurs gravures rupestres.

\section{Orant et bélier à « sphéroïde » (photo G. Camps)}

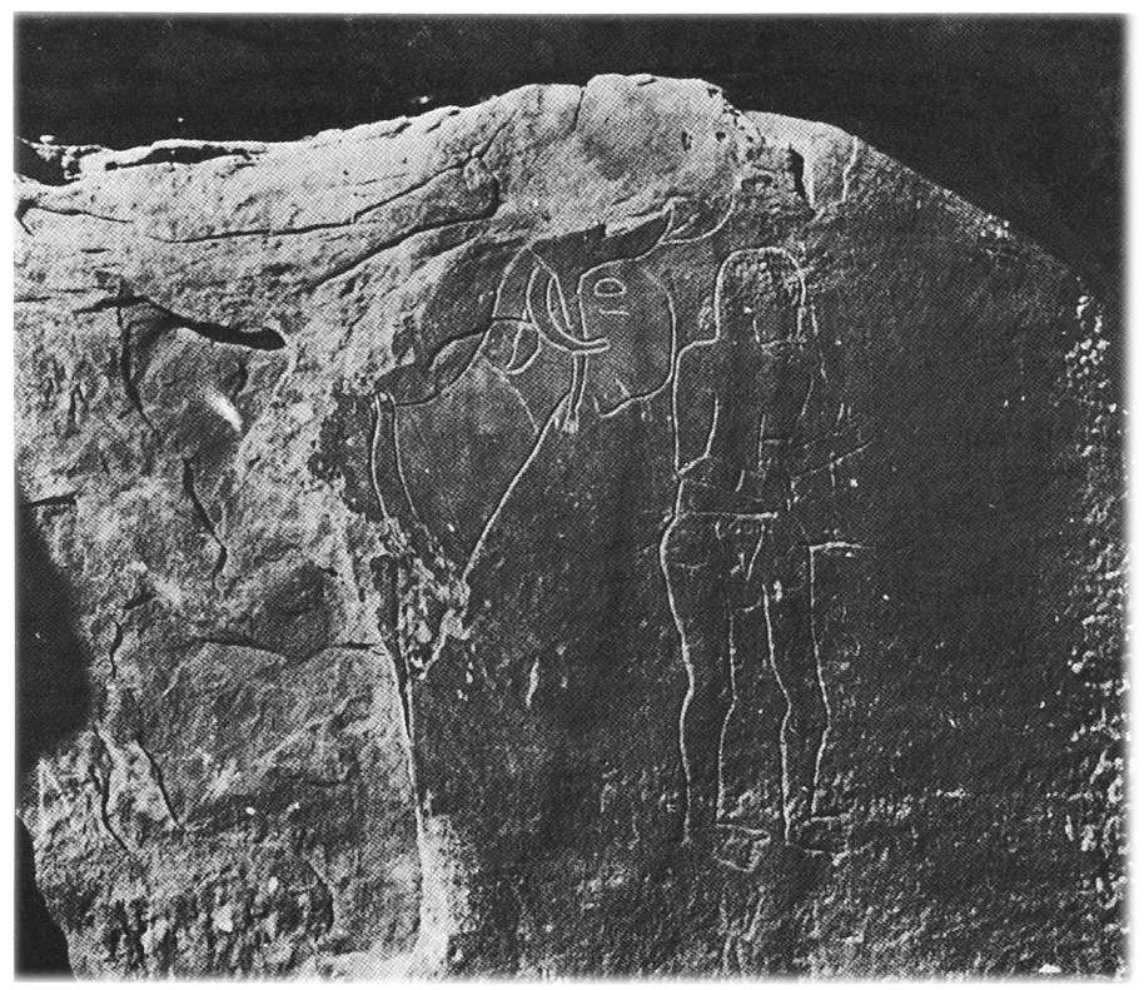

2 Le gisement présente, en stratigraphie, deux niveaux: Capsien et Néolithique. Caractérisé par un outillage microlithique, le Capsien d'Aïn Naga est un des plus anciens actuellement connus et se situe, selon les datations par le Carbone 14, dans les 
VIIIe et VIIe millénaires avant notre ère $(7350 \pm 300$ et $6950 \pm 280$ av. J.-C.). Le niveau supérieur néolithique est en fait un Capsien néolithisé en raison des très grandes similitudes de l'industrie à laquelle s'ajoutent seulement de la céramique et quelques outils à retouche bifaciale. Ce Néolithique est également très ancien. Il se place dans le VIe millénaire $(5550 \pm 220 \mathrm{av}$. J.-C.).

3 Les gravures sont dispersées sur plusieurs petites parois gréseuses entourant les jardins. Ce sont des scènes isolées. Les principales sont un combat de buffles (Homoïoceras antiquus) dans le style et les dimensions des plus belles représentations du Sud oranais, un grand personnage en position d'orant suivi d'un bélier à collier et attribut céphalique (voir bélier à sphéroïde*), deux grands personnages côte à côte et enfin un lapin sur la paroi d'un petit abri.

Aïn Naga : Les « amoureux timides » (relevé de J. Jalineck)

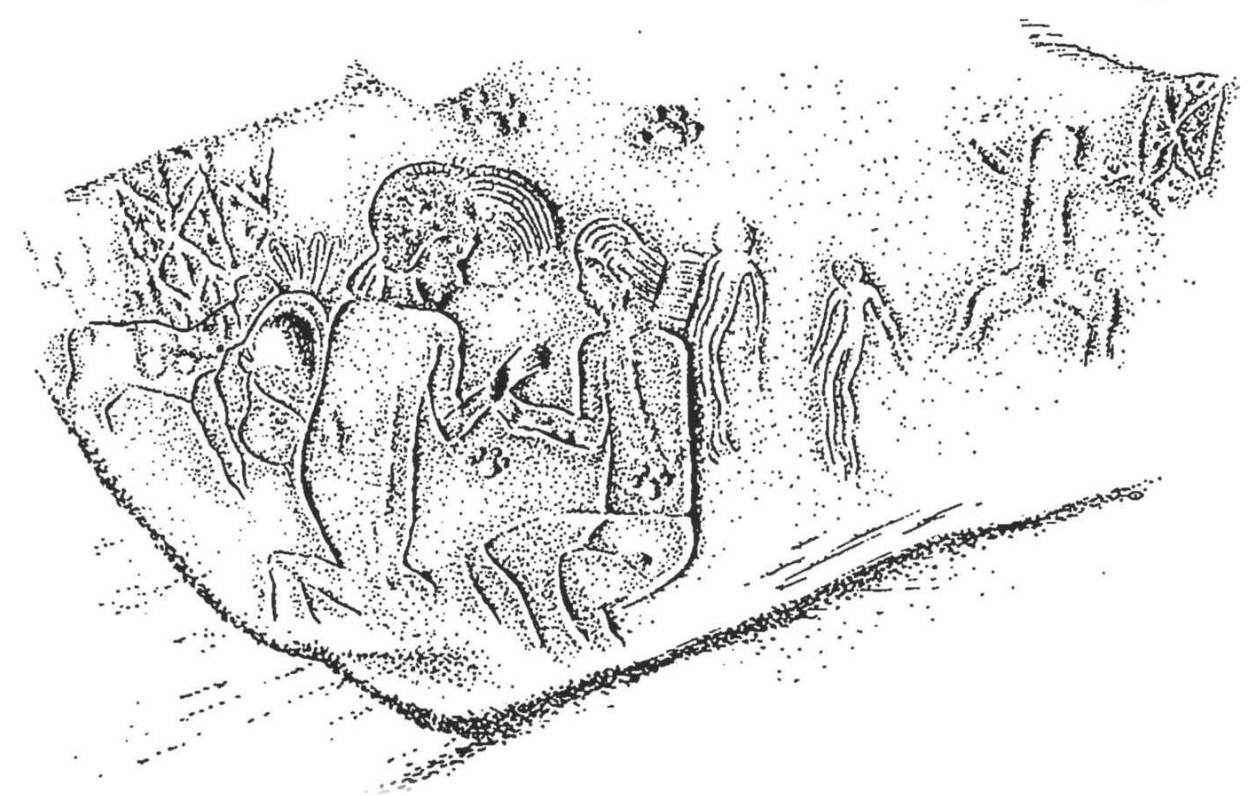

LHOTE H. avec le concours du Pére F. de Villaret. Les gravures rupestres de l'Atlas saharien. Mont des Ouled-Nail et région de Djelfa. Alger. 1984.

\section{BIBLIOGRAPHIE}

BIBLIOGRAPHIE

GREBENART D. Aïn-Naga : Capsien et Néolithique des environs de Messad (Dept. de Médéa. Algérie). Libyca, t. XVII, 1969, p. 135-198.

LETHIELLEUX J. Vestiges préhistoriques et protohistoriques de la région de Djelfa. Libyca, t. XIII, 1965, p. 249-265. 
HUARD P. et Allard L. les figurations rupestres de la région de Djelfa. Sud-algérois. Libyca, t. XXIV, 1976, p. 67-125.

INDEX

Mots-clés : Algérie, Art rupestre, Préhistoire 